\title{
Disability Work among Argentinean Patients with Rheumatoid Arthritis
}

\author{
Tamborenea Maria Natalia, Silvia Moyano Caturelli, Jackeline Spengler, Grisel Olivera Roulet
}

Servicio Nacional de Rehabilitación (SNR), Buenos Aires, Argentina.

Email: nataliatamborenea@hotmail.com

Received March 20 ${ }^{\text {th }}, 2012$; revised April 27 $7^{\text {th }}$ 2012; accepted May $9^{\text {th }}, 2012$

\begin{abstract}
Objective: 1) To analyze the prevalence of Work Disability (WD) in RA Argentinian patients who are attending at the National Rehabilitation Service (NRS); 2) To measure general, socioeconomics and disease characteristics in this population; 3) To characterize the associated factors of work disability in this group. Methods: Design cross section observational study. RA patients attending the NRS were included in consecutive form. Clinical, demographic and radiological data were collected. All patients answered about their employment status. WD was defined if the work status was unemployed due to RA, retirement prior to the normal age, or disabled pension. Comparing analysis among patients with and without paid work was done. Housewives, retired patients and students were excluded from the comparing analysis. Results: Three hundred and eleven patients were included $(\mathrm{n}=311)$. The prevalence of WD was 44.05\% $(\mathrm{n}=137)$. During the study $85(27.3 \%)$ patients were in paid employment, $48(15.3 \%)$ were retired, $39(12.5 \%)$ were housewives, and $2(0.6 \%)$ patients were students. Factor associated to WD were female sex, more than 5 years of disease duration, have health insurance, education beyond high school, and greater functional limitation: HAQ > 1 and function class 3 - 4. In the multivariable logistic regression model female sex was a significant and independent predictor of WD. Having health insurance; and more than high school education were protector factors of WD in this model. Conclusion: WD prevalence in this sample was higher than other countries. Socioeconomics factors more than diseases factors were significant predictors of productivity loss in this sample.
\end{abstract}

Keywords: HAQ; Work Disability; Rheumatoid Arthritis

\section{Introduction}

Rheumatoid Arthritis is a chronic disabling condition that may affect the lives of individual patients in many ways. One of most important outcomes may be work disability $[1,2]$.

Participation in paid employment is a major life role for most adults. People with arthritis can expect to be employed fewer years than the general population $[3,4]$ and withdrawal from paid employment, or work disability, is a relatively common outcome of RA. It results in lost income for the patient and less productivity for society [5].

Research into WD has been reported from USA and from European countries, rates of this outcome reported range from $22 \%$ to $85 \%$ [6].

Variations in estimated rates are likely due to differences in methods, subject selection, time, available treatments and definitions of work disability.

National Rehabilitation Service (NRS) in Argentina, evaluate patients with Rheumatoid Arthritis diagnosis who request Disability Certification according to 22431 law. This law establishes the conditions for grant the disability certificate. It is a public document issued by an interdisciplinary team that performs a biopsychosocial evaluation.

The National Disability Certificate is the admission key to the health system and the principal tool for the access to complete coverage of medication and rehabilitation.

In this study we analyze the prevalence of WD in RA patients who are attending at the National Rehabilitation Service (NRS) in Argentina and determine the associated factors to this outcome in this group.

\section{Patients and Methods}

RA patients are attending at the NRS for tramit the National Disability Certificate. They ask for this certificate in voluntary way and the population are from Buenos Aires province and rest of the all country.

From May 2008 to August 2008 RA patients were included in consecutive form in this cross section observational study. 
Clinical, demographic and radiological data were collected.

All patients answered about their employment status. The first question asked "main form of work" was unemployed, paid work, retired, housework, student or disabled.

WD was defined if the work status were unemployed due to RA, retirement prior to the normal age or disabled pension.

We analyzed the following characteristics about the disease: time of disease evolution, rheumatoid factor, functional class, radiographic erosions, HAQ-A and DAS 28 results.

For assess the association among disease characteristics and work status, were excluded for the analysis housework, students and retired patients.

\section{Statistical Analysis}

The sample was characterized using descriptive procedures.

To analyze categorical variables $\mathrm{X}^{2}$ were used and Student's $t$-test and Mann-Whitney test for continuous variables.

The main analysis was multivariable logistic regression to assess the roles of independent variables as predictors of work disability.

The logistic regression model was constructed with the following independent variables sex, education level, health insurance, years of disease evolution, functional class, anatomic class, HAQ-A and DAS28 results. We calculated odds ratios and $95 \%$ CIs. p values $<0.05$ was considered significant.

\section{Results}

Three hundred and eleven patients were included ( $\mathrm{n}=$ 311). The prevalence of WD was $44.05 \%(n=137)$.

Women were $87 \%(n=271)$ of the patients, the sample was predominantly middle aged (mean age 54 years), the median time of disease evolution was 8 (4 - 15) years. Around $75.8 \%(n=236)$ had some type of health insurance.

The $68.8 \%(n=214)$ of the sample have education beyond high school.

The HAQ-A score was bigger than 1 in $82.2 \%$ ( $=$ 256) of the patients and the DAS28 was more than 3.2 in the $83.3 \%(\mathrm{n}=259)$ of the sample. Function class was 3 or 4 in 199 patients $(64.2 \%)$ and radiographies erosions were present in $234(76 \%)$ patients. $91 \%(n=285)$ of the population was positive for rheumatoid factor test (Table 1).

During the study 85 (27.3\%) patients were in paid employment, 48 (15.3\%) were retired, 39 (12.5\%) were housewives, and $2(0.6 \%)$ patients were students (Table
1).

In the comparing analysis among patients with and without paid work, were excluded housewives, retired patients and students. To avoid expected retirement-related work cessation, subjects in our analysis were lower than 65 years old, remaining 223 patients for this analysis.

There were statistical significant differences when comparing characteristics among patients with and without WD, included gender (p: 0.001), more than 5 years of disease duration (p: 0.013), have health insurance (p: 0.005 ), education beyond high school (p: 0.000), and greater functional limitation: HAQ-A > 1 (p: 0.017) and function class 3 - 4 (p: 0.026) (Table 2).

In the multivariable logistic regression model female gender was a significant and independent predictor of WD p: 0.004 OR IC 95\% 3.2 (1.46 - 7.01). Having health insurance p: 0.01 OR IC 95\% 0.42 (0.21 - 0.81); and more than high school education p: 0.000 IC $95 \% 0.25$ (0.13 - 0.46) were protectors factors of WD in this model (Table 3).

Table 1. Sample characteristics of subjects $(\mathrm{n}=311)$.

\begin{tabular}{|c|c|}
\hline Women n (\%) & $271(87)$ \\
\hline Age, mean (range) & $54(25-77)$ \\
\hline Disease duration, median (IQR) & $8(4-15)$ \\
\hline Health insurance n (\%) & $236(75.8)$ \\
\hline$<$ High school education n (\%) & $214(68.8)$ \\
\hline Paid work n (\%) & $85(27.3)$ \\
\hline Retired n (\%) & $48(15.3)$ \\
\hline Housework n (\%) & $39(12.5)$ \\
\hline Students n (\%) & $2(0.6)$ \\
\hline Unemployed due to RA n (\%) & $111(35.7)$ \\
\hline Disabled pension n (\%) & $26(8.5)$ \\
\hline Rheumatoid factor + n (\%) & $285(91.6)$ \\
\hline Function classes 3 and 4 n (\%) & $199(64.2)$ \\
\hline Radiographic erosions n (\%) & $234(76)$ \\
\hline HAQ > 1 n (\%) & $256(82.3)$ \\
\hline DAS28 > 3.2 n (\%) & $259(83.3)$ \\
\hline
\end{tabular}


Table 2. Comparative analysis among patients with and without paid work $(n=223)$.

\begin{tabular}{cccccc}
\hline & WD n: 137 & No WD n: 86 & p & OR & $95 \%$ CI \\
\hline Women \% & $90 \%(124 / 137)$ & $74 \%(64 / 86)$ & 0.001 & 3.2 & $1.5-6.93$ \\
Disease duration > 5 years & $65.6 \%(90 / 137)$ & $48.8 \%(42 / 86)$ & 0.013 & 2 & $1.1-3.6$ \\
Health insurance & $56.9 \%(78 / 137)$ & $75.5 \%(65 / 86)$ & 0.005 & 0.4 & $0.2-0.8$ \\
RF + \% & $92.7 \%(127 / 137)$ & $95 \%(82 / 86)$ & 0.42 & 0.61 & $0.1-2.2$ \\
High school & $22.6 \%(31 / 137)$ & $54.6 \%(47 / 86)$ & 0.000 & 0.24 & $0.1-0.4$ \\
Radigraphic erosions & $77 \%(106 / 137)$ & $68.6 \%(59 / 86)$ & 0.146 & 1.5 & $0.8-2.9$ \\
Function classes 3 - 4 & $71.5 \%(98 / 137)$ & $56.9 \%(49 / 86)$ & 0.026 & 1.89 & $1-3.4$ \\
HAQ > 1 & $79.5 \%(109 / 137)$ & $65 \%(56 / 86)$ & 0.017 & 2.08 & $1-4$ \\
DAS28 > 3.2 & $86.8 \%(119 / 137)$ & $80 \%(69 / 86)$ & 0.185 & 1.6 & $0.7-3.5$
\end{tabular}

Table 3. Multivariable logistic regression model. Patients with and without paid work $(n=223)$.

\begin{tabular}{ccc}
\hline Variable & OR 95\% CI & p \\
\hline Women \% & $3.2(1.46-7.01)$ & 0.004 \\
Disease duration $>5$ years & $1.78(0.93-3.4)$ & 0.08 \\
Health insurance & $0.42(0.21-0.81)$ & 0.01 \\
High school & $0.25(0.13-0.46)$ & 0.000 \\
HAQ $>1$ & $1.81(0.88-3.71)$ & 0.1 \\
Function classes 3 - 4 & $1.3(0.64-2.68)$ & 0.45 \\
\hline
\end{tabular}

\section{Discussion}

The loss of productivity associated with RA disability places significant burden on patients, their families and society as a whole [7].

Work disability is defined in this article as work cessation due to RA, retirement prior to the normal age, or disability pension due to RA.

Rates of WD reported from USA and European countries range from $22 \%$ to $85 \%$ [6]. Recently Allaire et al. reported that $35.1 \%$ of RA patients in US were work disabled [8].

In this sample of RA Argentinean patients had the prevalence of WD was $44.05 \%$, higher than the last reports from other countries. Employment status was defined for us like Allaire's study [8].

We found high prevalence of female gender, mean age of 54 years old, mean disease duration of 8 years, and high scores in DAS28 and HAQ.

Education level previous of RA diagnosis was low, and lower than others population.

Factors associated with WD in this group were female gender, absence of medical care, more than 5 years of disease duration, low education level, worse functional class and high HAQ score (Table 2).

Several studies agreed that medical care and education status are important socioeconomics predictors of work loss. In the same form, functional class and HAQ are predictors related to the disease [9-11].

We didn't find association between radiographic damage and disability in this group. Recent studies have demonstrated weak relationships between damage and disability in the first 10 years of disease course. It appears that inflammation contributes much more to the level of disability during the first years of disease course, whereas radiographic progression contributes more strongly after about 10 years of disease duration [12]. In our study patients had 8 years of disease duration approximately and high score of DAS28.

In the multivariable analysis were significant and independent predictors of WD female gender, absence of medical plan and education below high school.

Female gender has been reported to be an independent risk factor for WD in RA in several studies. RA more frequently starts early in females indicating that females are exposed to the inflammation longer than males [13].

M. Wallenius et al. [14] found fourfold increased risk in females, and reported differences in pain perceptions and worse mental health among genders could contribute to this point.

Health insurance absence in our country is associated 
to difficulties in access to the medical system, delay to start specific treatment and less possibilities to obtain the new available drugs. It results in worse disease evolution and disability increase.

Fewer years of schooling often result in a physically demanding occupation with fewer possibilities for vocational rehabilitation [15].

The HAQ disability has been a correlate of permanent work disability in almost all studies [16-18]. In this sample HAQ wasn't a significant independent predictor of WD. However, this is a cross section study and HAQ score was measured at the moment of processing disability certificate, and not in the moment that the patient developed work loss.

There are several limitations in our study. Patients who ask for disability certificate have probably more severs forms of the disease, and in this point our results can be overestimated. Sample size of 311 patients does not allow extrapolating the results to all patients with Rheumatoid Arthritis in our country. In this study was not recorded the type of patient's work. Due to the study design, we can not establish a temporal relationship between disability and work loss.

In conclusion, our data suggest that work disability among persons with RA in Argentina is still a substantial problem. We need design prospective cohort studies to estimate the prevalence of WD in this country and identify the real impact of RA on paid work.

\section{REFERENCES}

[1] D. L. Scott and S. Steer, "The Course of Established Rheumatoid Arthritis,” Best Practice \& Research Clinical Rheumatology, Vol. 21, No. 5, 2007, pp. 943-967. doi:10.1016/j.berh.2007.05.006

[2] Saralynn and H. A. ScD, "Update on Work Disability in Rheumatic Diseases," Current Opinion in Rheumatology, Vol. 13, No. 2, 2001, pp. 93-98. doi:10.1097/00002281-200103000-00001

[3] K. Puolakka, H. Kautiainen, et al., "Monetary Value of Lost Productivity over a Five-Year Follow Up in Early Rheumatoid Arthritis Estimated on the Basis of Official Register Data on Patients' Sickness Absence and Gross Income: Experience from the FIN-RACo Trial," Annals of the Rheumatic Diseases, Vol. 65, No. 7, 2006, pp. 899-904. doi:10.1136/ard.2005.045807

[4] A. Joung, J. Dixey, et al., "How Does Functional Disability in Early Rheumatoid Arthritis Affect Patients and Their Lives? Results from 5 Years of Follow-Up in 732 Patients from the Early RA Study," Rheumatology, Vol. 39, No. 6, 2000, pp. 603-611. doi:10.1093/rheumatology/39.6.603

[5] A.-C. Rat and M.-C. Boissier, "Rheumatoid Arthritis: Direct and Indirect Costs,” Joint Bone Spine, Vol. 71, No. 6, 2004, pp. 518-524. doi:10.1016/j.jbspin.2004.01.003

[6] E. M. Barret, D. G. Scott, et al., "The Impact of Rheuma- toid Arthritis on Employment Status in the Early Years of Desease: A UK Community Based Study,” Rheumatology, Vol. 39, No. 12, 2000, pp. 1403-1409. doi:10.1093/rheumatology/39.12.1403

[7] A. A. Kalla and M. Tikly, "Rheumatoid Arthritis in the Developing World," Best Practice \& Research Clinical Rheumatology, Vol. 17, No. 5, 2003, pp. 863-875. doi:10.1016/S1521-6942(03)00047-0

[8] S. Allaire, F. Wolfe, et al., "Contemporany Prevalence and Incidence of Work Disability Associated with Rheumatoid Arthritis in US," Arthritis Care \& Research, Vol. 59, No. 4, 2008, pp. 474-480. doi:10.1002/art.23538

[9] A. Young, J. Dixey, et al., "Which Patients Stop Working Because of Rheumatoid Arthritis? Results of Five Years' Follow Up in 732 Patients from the Early RA Study (ERAS)," Annals of the Rheumatic Diseases, Vol. 61, No. 4, 2002, pp. 335-340. doi:10.1136/ard.61.4.335

[10] M. J. Plant and M. M. O’Sullivan, "What Factors Influence Functional Ability in Patients with Rheumatoid Arthritis. Do They Alter over Time?” Rheumatology, Vol. 44, No. 9, 2005, pp. 1181-1185. doi:10.1093/rheumatology/keh707

[11] K. Puolakka, H. Kautiainen, T. Möttönen, et al., "Predictors of Productivity Loss in Early Rheumatoid Arthritis: A 5-Year-Follow-Up Study," Annals of the Rheumatic Diseases, Vol. 64, No. 1, 2005, pp. 130-133. doi:10.1136/ard.2003.019034

[12] T. K. Kvein, "Epidemiology of Disability in Rheumatoid Arthritis,” Rheumatology, Vol. 41, No. 2, 2002, pp. 121123. doi:10.1093/rheumatology/41.2.121

[13] T. K. Kvien, T. Uhlig, et al., "Epidemiological Aspects of Rheumatoid Arthritis: The Sex Ratio," Annals of the New York Academy of Sciences, Vol. 1069, 2006, pp. 212-222. doi:10.1196/annals.1351.019

[14] M. Wallenius, J. F. Skomsvoll, et al., "Comparison of Work Disability and Health-Related Quality of Life between Males and Females with Rheumatoid Arthritis below the Age of 45 Years," Scandinavian Journal of Rheumatology, Vol. 38, No, 3, 2008, pp. 178-183. doi:10.1080/03009740802400594

[15] A. Macedo, S. Oakley, et al., “An Examination of Work Instability, Functional Impairment, Ant Disease Activity in Employed Patients with Rheumatoid Arthritis," The Journal of Rheumatology, Vol. 36, No. 2, 2009, pp. 1-6. doi:10.3899/jrheum.071001

[16] C. Han, J. Smolen, et al., “Comparision of Employability Outcomes among Patients with Early or Long-Standing Rheumatoid Arthritis," Arthritis Care \& Research, Vol. 59, No. 4, 2008, pp. 510-514. doi:10.1002/art.23541

[17] S. Lillegraven and T. K. Kvien, "Measuring Disability and Quality of Life in Established Rheumatoid Arthritis," Best Practice \& Research Clinical Rheumatology, Vol. 21, No. 5, 2007, pp. 827-840. doi:10.1016/j.berh.2007.05.004

[18] P. Katz and A. Morris, "Subclinical Disability in Valued Life Activities among Individuals with Rheumatoid Arthritis,” Arthritis Care \& Research, Vol. 59, No. 10, 2008, pp. 1416-1423. doi:10.1002/art.24110 